\title{
Time and Distance Heterogeneity in the Neighborhood Spillover Effects of Foreclosed Properties
}

\author{
Lei Zhang, Tammy Leonard \& James C. Murdoch
}

February 24, 2015 


\begin{abstract}
In this paper we examined heterogeneity in the simultaneous space-time impact of foreclosures on neighborhood property values. Foreclosures with longer foreclosure processes were associated with negative neighborhood price externalities from the time the foreclosing household still had ownership of the property and continued through the Real Estate Owned (REO) period. However, foreclosures with shorter foreclosure processes were associated with negative neighborhood price externalities that did not occur until at least 3 months after the foreclosure auction and were much smaller in magnitude. Results suggest a negative neighborhood effect of extending the length of the foreclosure process. Policy encouraging foreclosure "workout" efforts, which when unsuccessful extend the duration of the foreclosure process, should take these additional price externalities into account.
\end{abstract}

Keywords: Hedonic model; Foreclosures; Heterogeneity 


\section{Introduction}

Several authors have found negative neighborhood price impacts associated with foreclosed properties (Immergluck and Smith, 2006; Schuetz et al., 2008; Harding et al., 2009; Leonard and Murdoch, 2009; Lin et al., 2009; Rogers and Winter, 2009; Daneshvary et al., 2011; Daneshvary and Clauretie, 2012) but the geographic extent and magnitude of these foreclosure price externalities vary.

There are many reasons to expect geographic variation in foreclosure price externalities including differences in housing market fundamentals, state laws and the density of foreclosures. However, within a single urban market, there are no differences in the legal process governing foreclosures and relatively fewer differences in housing density, urban form and local market fundamentals. Our goal was to examine whether there was variation in the price impacts of foreclosure within a single urban market and to assess whether these within market differences compared in magnitude to the cross market differences observed in the literature. While controlling for local neighborhood historical price trends and neighborhood foreclosure activity, we estimated foreclosure price externalities across space and time for two types of REO foreclosures: those that terminated in a market sale of the property within 2 years following the foreclosure auction and those that took more than 2 years to be re-sold. We then compared these effects and discussed how observed heterogeneity in price externalities might inform about the mechanisms generating the price externalities.

\section{Background \& Hypothesis}

\subsection{The Foreclosure Process}

Foreclosure processes vary by state. In Texas, the study area of this paper, the most common type of foreclosure is a non-judicial foreclosure. Non-judicial foreclosures 
generally proceed more quickly because the foreclosure process does not require court intervention. In the United States, non-judicial foreclosure is the most common type of foreclosure in 28 of the 50 states (Mortgage Bankers Association, 2014).

To initiate a non-judicial foreclosure, the lender sends a notice of default to the defaulted borrowers and must allow the homeowner at least 20 days to cure the default before the notice of sale is sent. Next, the notice of sale must be sent to the borrower at least 21 days before the foreclosure sale. After the 21-day period, the property in default may be sold through auction to the highest bidder. At auction, the bank sets an opening bid that is generally high enough to cover the outstanding mortgage balance, plus interest, penalties, and other legal fees. If there are no higher bids, the bank may take possession of the property. The bank-owned foreclosed property is then classified as part of the bank's REO stock. Since the bank's opening bid at auction is usually greater than the current market value of the property, most foreclosures that go to auction end up in REO stock. Once in REO stock, foreclosed properties are returned to the housing stock through a successful market sale ${ }^{1}$.

The "foreclosure process" encompasses the time period from the first notice of default until the successful market sale. Even though in principle the foreclosure process appears quite uniform, the time duration of the process varies widely. For example, while banks may send the notice of sale 20 days after the notice of default, they are not required to act so quickly. Banks may be slower to act when foreclosure volume is high or when the property is less desirable (and hence less valuable as REO stock). Additionally, properties will spend varying amounts of time in REO stock depending upon both how willing the bank is to negotiate a market sale and the market conditions for the type and quality of house.

\footnotetext{
${ }^{1}$ Sometimes, the foreclosure process terminates prior to a transfer of ownership either because the first owner becomes current on their mortgage or the lender modifies the loan. Modifications became increasingly utilized with the passage of new legislation in 2009 (e.g., Making Home Affordable Plan and the Home Affordable Modification Program) as a response to the financial crisis that began in 2007 (Stewart, 20I0).
} 


\subsection{Mechanisms for Foreclosure Price Externalities}

Variations in the impact of foreclosures within a single housing market may be examined in light of the different channels through which foreclosures produce neighborhood price externalities. There are three primary channels: blight, valuation, and supply (Lee, 2008). These channels are distinct with respect to both the mechanism through which the externality is generated and the timing of the external impact. The blight channel occurs because foreclosed properties are poorly maintained and may produce negative price externalities before the official declaration of foreclosure or during the foreclosure process. The valuation channel occurs because foreclosed homes often sell at a discount and may produce negative neighborhood price externalities immediately following a market sell of a foreclosed property. The supply channel occurs because foreclosed homes "recycle" back to the market and increase the supply of houses on the market. The negative price externalities created by the supply channel may occur any time after the foreclosure event because foreclosed properties can re-enter the market at auction, short sales, or when properties sale out of REO stock.

Only the blight channel is at work prior to the initiation of foreclosure. If only foreclosures which become REO stock are considered, then the blight channel is also the only channel at work during the foreclosure process. The valuation and supply channels are potentially at work after a market sale of the foreclosed property. Harding et al. (2009) found that, for REO properties, the greatest neighborhood price impacts occurred before the market sale of the foreclosed property. More precisely, the price externalities occurred around the time that the property changed hands from the foreclosing homeowner to the bank holding the failed mortgage. Therefore, for REO properties, variations in the blight channel are the most likely source of heterogeneity in the degree of neighborhood price externalities.

\subsection{Estimates of Foreclosure Price Externalities}

Robust and diverse results indicate that foreclosures are associated with negative price 
impact on nearby house sales and the impact decays with increasing distance from the foreclosing property. Within a block, estimated neighborhood foreclosure price externalities ranging from $1 \%$ to $9 \%$ of home value have been reported (Immergluck and Smith, 2006, and Lin, et al., 2009, among others). Additionally, foreclosure price externalities varied with different stages of the foreclosure process. Lee (2008)'s review of 10 empirical foreclosure studies provides evidence of heterogeneity in the neighborhood price effects of foreclosures.

Examining the Chicago, IL housing market, Immergluck and Smith (2006) found that foreclosures within an eighth of a mile of a single-family home resulted in home value declines of 0.9 percent. Using data in New York City, Schuetz, et al. (2008) estimated that foreclosure price externalities within 250 feet of a foreclosed property ranged from $0.2 \%$ to $0.4 \%$. In the Chicago Primary Metropolitan Statistical Area the most severe impact was an $8.7 \%$ discount on neighborhood properties located within 100 meters and sold within two years after the foreclosure (Lin et al., 2009). In Dallas County, Texas, the distance effects were similar, but the price impacts were considerably smaller (i.e. less than 1\%) (Leonard and Murdoch, 2009). Using data on REO properties from 7 Metropolitan Statistical Areas, Harding et al. (2009) classified a property as being in the foreclosure process from 12 months before the foreclosure sale date until 12 months after the REO sale date. Both the magnitude of the neighborhood price impact and the speed of distance decay differed by geographic region. Rogers and Winter (2009) measured the impact of foreclosures on housing sales using a dataset from St. Louis County, Missouri. Results showed foreclosure within 200 yards and 6 months since the observed sale had an approximate 1\% negative impact on neighborhood sales. Daneshvary, et al. (2011) concentrated on the short-term contemporaneous own-price discount and the spillover effects of short sales, sales in the process of foreclosure, and REO. They estimated 1\% price discounts within 0.1 miles. Wassmer (2011) used data from January 2008 to June 2009 in Sacramento, California area to explore the 
foreclosure impact during the financial crisis. The results showed that an additional REO property sold within a tenth of a mile reduces the selling price of a home by $0.61 \%$.

Comparison of the magnitudes of estimated foreclosure price externalities reveals that the negative impacts are quite diffuse and certainly neighborhood price externalities appear to vary across markets. Zhang and Leonard (2014) documented heterogeneity in the neighborhood price impacts of foreclosure within a single market by estimating a quantile regression model. However, evidence regarding the heterogeneity of the foreclosure impact on neighborhood sales according to duration of the foreclosure process is lacking.

In this paper, we focus on heterogeneity in the simultaneous space-time impact of foreclosures on neighborhood property values attributable to differing lengths of time in the foreclosure process.

\subsection{Measurement of Foreclosure Price Externalities}

In the analysis that follows, we used Harding et al. (2009)'s framework for controlling for the simultaneous space and time variations in the neighborhood price impacts. However, we examined the impact for two mutually exclusive groups of foreclosures: those for which the foreclosure process was relatively short and those for which the foreclosure process was lengthy. Hereafter, we refer to foreclosure processes that culminate in a market sale within 2 years of the foreclosure auction as "resolved within 2 years" (RW2); and those that do not as "unresolved within 2 years" (UW2). By closely following the space-time approach of Harding et al. (2009), we are able to compare our results for the 2 different types of foreclosure processes with those estimated for the "average" foreclosure process. In related work, the space-time approach of Harding et al. (2009) was also implemented in the Dallas County housing market to analyze neighborhood variation in foreclosure externalities (Zhang \& Leonard, 2014) and we can compare our results to this work as well. 
Rather than utilizing the repeat sales methodology of (Harding et al., 2009) we used spatial econometric modeling techniques as presented in Leonard and Murdoch (2009) to control for unobserved neighborhood characteristics and local house price trends that if not adjusted for likely bias the estimated price impact of foreclosure ${ }^{2}$. The spatial econometric approach for dealing with these unobserved neighborhood level attributes allowed us to estimate the price impact of foreclosure using all housing sales transactions rather than just those for which we observed a repeat sale. This was an especially important distinction when estimating the price impacts of foreclosure because the likelihood of observing a repeat sale may be related to the likelihood of having neighborhood foreclosures.

Daneshvary et al. (2011) also used spatial econometric hedonic models to examine price externalities associated with different types of foreclosure processes. They found that foreclosures in Las Vegas, NV which were resolved through a short-sale produced no detrimental price externalities, but foreclosures which ended in REO produced price externalities within the range of those found by other authors. However, they were only able to estimate the price impacts of foreclosures a maximum of 6 months after the distressed sales. We extended their work by estimating the complete time-space impacts of different durations of REO foreclosure from 1-year prior to the foreclosure auction through more than 1 year after the auction. Additionally, our data came from the Dallas County housing market, which has remained more stable throughout the financial recession.

\subsection{Hypothesis}

Any price externalities observed prior to the end of the foreclosure process for REO properties should be a consequence of blight. We hypothesize, that UW2 REO properties

\footnotetext{
${ }^{2}$ See Rogers and Winter (2009), and Kobie and Lee (20II) for other applications using spatial econometric specifications.
} 
(i.e. those properties that did not resell within 24 months after foreclosure auction) produce larger negative price externalities during the foreclosure process. We base this hypothesis on the assertion that severity of the blight channel is likely related to the length of the foreclosure process; however, we acknowledge that causality in this relationship may go either way (i.e. a property in poor condition could cause the foreclosure process to be longer; or a property could fall into poor condition because of a long foreclosure process). The trend in the magnitude of neighborhood price externalities will help to illuminate the direction of causality. We hypothesize that a longer duration in REO stock causes blight. Thus, we expect to see that the difference in foreclosure price externalities for UW2 and RW2 properties widen as properties remain in REO stock for longer periods of time. Finally, most of the extant literature estimates foreclosure externalities that diminish quickly with distance. Therefore, our third hypothesis is that foreclosure price externalities will decay quickly with distance for both RW2 and UW2 foreclosures.

\section{Data and Estimation Strategy}

\subsection{Data}

Our data comes from real-estate transactions and foreclosures recorded in Dallas County, Texas. All arm's length housing transactions recorded by the multiple listing service (MLS) from 2004 to 2011 were obtained from the University of Texas at Dallas Real Estate Research Database. This database contains historical records on housing characteristics, appraised values, sale prices, and various types of sales. We used the sales prices for properties sold in 2008 as the dependent variable and other housing transactions were used to determine the duration of foreclosure process for houses that foreclosed between 2004 and 2009. Using houses that sold in 2008 as the dependent variable allowed us to examine the price impact of foreclosures that occurred in the wake of the Great Recession. Detailed variable descriptions are presented in Table 1. The average home sold for 
approximately \$250,000, had 2,100 square feet of living area, two bathrooms, and was 36 years old.

A list of foreclosures in REO stock from 2004 to 2009 were obtained from RealtyTrac and used to identify homes that foreclosed. RealtyTrac records all filings made on a property as it goes through the foreclosure process including default notice, auction sale notification and bank repossession (Kan, 2008). 3 The foreclosure data were geocoded and spatially merged to the real estate database to facilitate calculation of neighborhood foreclosures and to identify different types of foreclosure based on duration of the foreclosure process. Of the 33,045 foreclosures observed from 2004 to $2009,10,787$, or $33 \%$, were categorized as RW2 because they re-sold through a transaction recorded by the multiple listing service (MLS) within 24 months following the foreclosure auction. Another 22,258, or 67\%, were categorized as UW2 because they were not re-sold through the MLS within 24 months. A 24-month time horizon was used to distinguish between long and short foreclosure processes based upon the duration of foreclosure processes in our data. 97 percent of foreclosures for which a market sale could be found in the MLS data had foreclosure processes that ended less than 24 months after the auction date. The foreclosure process in Texas under "normal" market conditions averages 245 days (TDHCA, 2006). We allow additional time to account for the slower housing market following the great recession.

For each house that sold in 2008, the foreclosure data was summarized by counting the number of foreclosures in several time and distance threshold categories. We categorized the distance between each market sale property and foreclosed properties by using two concentric rings with different radii measured by Euclidean distance in feet: 0-250 feet (ring 1), and 250- 500 feet (ring 2)4. Following Harding et al. (2009), the time

\footnotetext{
${ }^{3}$ See Kan (2008) for a comparison of foreclosure data sources including RealtyTrac data.

${ }^{4}$ We follow literature (such as Schuetz, et. al (2008), and Leonard and Murdoch (2009) among others) to determine the distance rings. We do not include farther rings since past literature, as well our model, indicates foreclosures in farther rings, such as 500-IO0o feet, IOOO-I500 feet, do not have significant negative impact on
} 
effects were categorized according to the phase of the foreclosure process at the time of a market sale. We considered 9 different 3-month time windows beginning 12 months before the initiation of the formal foreclosure process. Figure 1 depicts the different time categories. We broke the time before foreclosure auction (F) into four periods, and the time after $\mathrm{F}$ into five periods. We defined the last post-F period to include all properties that had been in the foreclosure process for more than 12 months. For example, if a house sold in January 2008, then foreclosures that occurred in January 2009 (12 months in the future) would be counted in the F-12 phase, and foreclosures that occurred in January 2007 (12 months previous) would be counted in the $\mathrm{F}+12$ phase. All earlier foreclosures (i.e. foreclosures occurring from 2004-2006) would be counted in the $>F+12$ phase. We include the $>\mathrm{F}+12$ phase to measure the long-term foreclosure impact. Finally, we counted the number of foreclosures associated with each market sale by time and distance creating a total of 18 possible time-space combinations.

\subsection{Estimation Strategy}

We estimated spatial hedonic price models (Rosen, 1974; Kim et al., 2003) that controlled for property and neighborhood characteristics. The basic model was as follows:

$$
P_{08}=\beta X_{08}+\gamma D_{08}+\sum_{t=05}^{08} \rho_{t} W_{t} P_{t}+\sum_{d=1}^{2} \sum_{p=1}^{9} \alpha_{d p} R_{d p}+\sum_{d=1}^{2} \sum_{p=1}^{9} \delta_{d p} U_{d p}+\varepsilon
$$

$P$ is the vector of natural log of market sale prices and the subscript denotes the year (e.g., 08 for 2008). $X$ is a matrix of property characteristics (e.g., living area in square feet, number of bathrooms, age of the house, etc.), and $D$ is a matrix of dummy variables that control for fixed effects due to school districts and the month in which the sale took place5. The monthly dummies controlled for seasonal effects in home prices (Goodman, 1993). $W_{t} P_{t}$ is the spatial weighted average of nearby sale prices in year $t$ and was included

\footnotetext{
nearby house sales. The results for models which include the farther rings are available from the authors upon request.

${ }^{5}$ Observations used only correspond to non-foreclosed transactions.
} 
in the model for $t=2005$ through $t=2008$ to control for the trend in neighborhood price levels. Parcels within a straight-line distance of 2000 feet of each 2008 sale were considered neighbors. Each element of the spatial weight matrix $W$ was calculated based on the inverse distance from sales in year $t$ to sales in year 2008. For any property greater than 2000 feet away, the corresponding element in the weight matrix was set to zero. Finally, all of the weights matrices were row standardized. Matrix $R_{d p}$ contains the number of RW2 foreclosures at distance $d$ and foreclosure period $p$, while $U_{d p}$ contains the count of UW2 foreclosures for each time-space bucket. The sets of coefficients, $\propto_{d p}$ and $\delta_{d p}$, measure the marginal spillover effect of additional RW2 or UW2 neighborhood foreclosures, respectively.

Because $P_{08}$ appears on the left and the right hand side of the model, equation (1) is a classic spatial lag model that is not amenable to OLS estimation (Anselin, 1988). Instead maximum likelihood estimation was used to provide consistent parameter estimates (Lee, 2004). We estimated three different specifications. Model 1 only included time effects. Thus, for Model 1, the vectors $R$ and $U$ in equation (1) included the counts of foreclosures at each time interval that were within 500 feet of the reference property. Next, Model 2 only considered distance effects and lumped all of the time effects together. For Model 2, $R$ and $U$ included the counts of all 2004-2009 foreclosures in each concentric ring around the reference property. Foreclosures may have been in any stage of the foreclosure process. Finally, Model 3 was estimated with both time and distance effects simultaneously.

The model in (1) is based upon an implicit assumption that RW2 and UW2 foreclosures produce different neighborhood price externalities. To test this assumption, we conducted a likelihood ratio (LR) test of equality of RW2 and UW2 parameter estimates. The test's null hypothesis was that the coefficients of RW2 foreclosures are jointly not different from the coefficients of UW2 foreclosures. We were able to reject this 
hypothesis at a 99.9\% confidence level for all 3 models ${ }^{6}$.

\section{Results}

Table 2 reports coefficient estimates for all models, excluding estimates describing the foreclosure price externalities. Estimates for the foreclosure time effects in Model 1 and distance effects in Model 2 are reported in Table 3; and estimates of the joint timedistance effects from Model 3 can be found in Table 4. Note that the models explain more than $80 \%$ of the total variation in the dependent variable.

In Table 2 we see that in all models the estimated coefficients for house characteristics, school district fixed effects and time fixed effects are as expected. Additionally, the estimates on the local neighborhood price trends are all positive and statistically significant, highlighting the importance of including these variables.

\subsection{Time Effects}

The upper panel of Figure 2 displays the estimated neighborhood price externalities resulting from foreclosures within 500 feet of a non-distressed sale as estimated in Model 1. All of the coefficients are converted to percentage change of sales price using a logarithm transformation7. The two series in the figure - one for RW2 foreclosures, and the other for UW2 foreclosures - clearly indicate that the effect varies with the period and type of the foreclosure. The dotted and dashed lines represent 95\% confidence intervals for RW2 and UW2 foreclosures separately. For RW2 foreclosures, the negative spillover effects do not significantly affect the neighborhood sales price until 3 months after the property becomes REO. However, for UW2 foreclosures, the negative impact starts as early as 12 months prior to the foreclosure auction. The negative impact continues

\footnotetext{
${ }^{6}$ Model I: LR test statistic $=$ I39.9, $\mathrm{p}$ value $=0$; Model 2: $\mathrm{LR}$ test statistic $=47 . \mathrm{I}, \mathrm{p}$ value $=\mathrm{O} ;$ Model 3: $\mathrm{LR}$ test statistic $=166.3, p$ value $=0$

${ }^{7}$ Percentage change $=e^{\alpha}-\mathrm{I}$.
} 
through the foreclosure process, and reaches the strongest level in the periods immediately following the foreclosure auction. In comparing RW2 and UW2 foreclosures, it is apparent that UW2 foreclosures have stronger and earlier negative impacts than RW2 foreclosure. Differences diminish in later periods of the foreclosure process.

\subsection{Distance Effects}

Next, we examine the aggregate distance effects (Figure 2 lower panel) as estimated in Model 2. For both RW2 and UW2 foreclosures, the spillover effect is strongest within 250 feet from the reference property. Within Ring 1, the price impact of UW2 foreclosures is larger (in absolute value) than the similar impact of RW2 foreclosures. However, the difference between RW2 and UW2 foreclosures diminishes in the subsequent ring8.

\subsection{Simultaneous Time and Distance Effects}

Simultaneous time and space price impacts of neighborhood foreclosures estimated in Model 3 are presented in Table 4 for RW2 and UW2 foreclosures. Now there are a total of 18 different time-space foreclosure variables ( 9 time intervals $\times 2$ distance intervals) for which effects are estimated. With so many different time-space buckets possible, it is more difficult to find statistically significant results. The upper panel of Figure 3 presents the percentage change in house prices as a result of additional RW2 or UW2 foreclosures in ring 1 based on the estimates from Model 3. The trend is similar to the aggregate time effects displayed in the upper panel of Figure 2, but the magnitudes are much larger. The larger price impacts are expected in Figure 3 (upper panel) because only the closest foreclosures (those occurring within 250 feet of the reference property) were included in the estimated effects. When other variables are held constant, each additional foreclosure within 250 feet of a house results in an expected property value decrease of up to $4 \%$ (RW2) or 17\% (UW2). Given an average sales price of $\$ 250,881$ in Dallas County, these

\footnotetext{
${ }^{8}$ We also examined a model with two more outer rings, 500-Iooo feet and Iooo-I50o feet. The main result remained: the heterogenous effects between RW2 and UW2 foreclosures disappeared in outer rings.
} 
effects imply decreases in value of approximately $\$ 10,035$ and $\$ 42,650$, respectively.

The lower panel of Figure 3 presents the percentage change in house prices associated with additional foreclosures for ring 2. The estimates for UW2 foreclosures are statistically significant during the early stages of the foreclosure process. The price externalities associated with RW2 foreclosures are mainly insignificant. However, in general, the difference between RW2 and UW2 foreclosures is not statistically distinguishable in ring 2.

\subsection{Robustness Check}

There are two primary concerns with the models estimated thus far: (1) omitted unobserved neighborhood conditions that are correlated with home price but not captured in the spatial lag term and (2) endogeneity in the classification of RW2 and UW2 foreclosures. We deal first with the potential for omitted neighborhood conditions which may cause lower home prices and in turn an increased chance of future foreclosures (e.g. Rogers and Winter, 2009). A spatial autoregressive models with spatial autoregressive disturbances (SARAR $(1,1)$ ) will control for this possibility (Daneshvary et al., 2011). We ran a SARAR $(1,1)$ model and found that our main conclusion of foreclosure heterogeneity effects was not affected. All estimated results are available from the authors upon request.

As for the issue of endogeneity between the occurrence of UW2 foreclosures and home sale prices, it is possible that there was some unobserved neighborhood characteristic which simultaneously increased the likelihood of observing an UW2 foreclosure and a lower home sale price. We test this first, by analyzing spatial patterns in the time from auction to market sale for properties for which a market sale was observed9. If there is serious endogeneity in the classification of RW2/UW2, we would expect there might be a spatial pattern in the time to resolution data. We performed

\footnotetext{
${ }^{9}$ These include all RW2 foreclosures as well as foreclosures for which a market sale was observed more than 24 months after the foreclosure auction
} 
Getis-Ord-Gi* hotspot analysis (ESRI, 2014) using inverse-distance weighting to formally test the degree of spatial clustering in the time to resolution data. Only 546 (4.9\%) of the foreclosures exhibited patterns of clustering that were statistically significant at a $95 \%$ level. In other words, over $95 \%$ of the foreclosure durations were consistent with the null hypothesis that the time between auction and sale exhibits a spatially random pattern.

Despite the fact that spatial clustering in foreclosure duration is rare, we cannot completely rule out the possibility of endogeneity. In all of our previously presented models, we included local neighborhood price trends from 2005 to 2008 to account for possible endogeneity, but it is possible that endogeneity remained. To test for this, we used the Durbin-Wu-Hausman test. The test indicated that local neighborhood price trends did not fully explain the ratio of UW2 to RW2 foreclosures in the neighborhoods around each of the market $\operatorname{sales}^{10}$. Since the potential endogeneity is related to an increased likelihood of observing one type of foreclosure over another, we estimated an additional model ${ }^{11}$ that explicitly included the percentage of foreclosures that were classified as UW2 within 2000 feet of each sale. The model also included all of the other covariates found in Model 3. The estimated coefficient for the new variable measuring the percentage of UW2 foreclosures is 0.104 and is significant at the $1 \%$ level. However, the presence of this previously omitted variable did not significantly change the neighborhood price impacts of foreclosure. All other coefficient estimates in this model are similar to those observed in Model 3. Thus, we conclude that a tendency for some neighborhoods to be associated with a larger number of UW2 foreclosures is not fully explained by the local neighborhood price trends which we include in all of our models, but it also does not account for the observed differences in the price impacts of RW2 and

\footnotetext{
${ }^{10}$ To test for this, we applied a Durbin-Wu-Hausman test to test if the ratio of the number of UW2 foreclosures to the number of both types of foreclosures within 2000 feet of a market sale was endogenous. Lagged spatial weighted average of neighborhood sale prices (our WtPt terms in equation (I)) were used as instruments. The test failed to reject the null hypothesis that the ratio was exogenous.

${ }^{11}$ Results are available from the author upon request.
} 
UW2 foreclosures.

To further uncover if endogeneity between the occurrence of UW2 foreclosures and home sale prices affected the observed differences in the price impacts of RW2 and UW2 foreclosures, we employed an instrumental variables approach. We used local housing market activity as an instrument for the probability that a foreclosure was classified as RW2 (instead of UW2). Housing market activity was defined as the number of MLS transactions that occurred within 2000 feet of each foreclosed property during the year that the property foreclosed. We used a probit model to estimate the probability of a foreclosure being classified as RW2:

$$
\operatorname{Pr}\left(Y_{i}=y_{i}\right)=f\left(x_{i}, d_{i}, s_{i}\right)
$$

where

$$
y_{i}=\left\{\begin{array}{l}
1 \text { if the } i \text { th foreclosure is RW2 } \\
0 \text { if the } i \text { th foreclosure is UW2 }
\end{array}\right.
$$

$x_{i}$ includes all of the property characteristics for foreclosed house $i$, and $d_{i}$ includes all of the dummy variables that control for fixed effects due to school districts and the month in which the sale took place ${ }^{12} . s_{i}$ is the number of market sales within 2000 feet of the foreclosed property that occurred during the same calendar year as the foreclosure.

We used parameter estimates from (2) to compute the predicted probability of a foreclosure being classified as RW2. We then reclassified all foreclosures based upon the predicted probabilities. If an estimated probability was greater than 0.5 , then the foreclosure was classified as RW2; otherwise, it was classified as UW2.

Finally, we used the re-classified RW2 and UW2 foreclosures to obtain new estimates for Model 3. The housing characteristics data that was required for the probit model was not available for about $40 \%$ of the observations. Therefore, we used a reduced

\footnotetext{
${ }^{12} x i$ and $d i$ are similar to the variables included in equation (I).
} 
sample in this estimation ${ }^{13}$. We find that the differences in the price externalities of RW2 and UW2 foreclosures still exist even after accounting for potential endogeniety associated with how we classified foreclosures ${ }^{14}$.

\section{Discussion}

The purpose of this study was to examine heterogeneity in the simultaneous space-time impact of foreclosures on neighborhood property values based on different types of foreclosure outcomes. We found considerable heterogeneity in price impacts. We found that, if the foreclosure was within 250 feet of the market sale, for RW2 foreclosures, there was a single small statistically significant price externality (4\%) in the period of $3-6$ months after the property became part of the REO stock. The magnitude of the price impacts in line with results reported for other metro-areas. However, for UW2 foreclosures, the negative impacts started as early as 12 months prior to the foreclosure auction and lasted over 12 months after the property entered REO stock. The negative impact for UW2 foreclosures reached its strongest level in the months immediately following the foreclosure auction. These results substantively held after controlling for potential endogeneity associated with the classification of RW2/UW2 foreclosures.

Our study does have limitations that should be considered when examining the results. First, the data was drawn from a single county-Dallas County, TX. Dallas County was not an area examined by Harding et al. (2009) and the housing market was less volatile than markets in many other metro areas during the financial recession; however, our general space-time results are consistent with others reported in the literature across a variety of markets. Limiting our study to one area was advantageous for isolating the impact of with-in market heterogeneity in foreclosure outcomes, but certainly the

\footnotetext{
${ }^{13}$ The sample size is 7,468 .

${ }^{\mathrm{I} 4}$ Results are available from the authors upon request.
} 
external validity to other markets should be tested.

We hypothesized that UW2 REO properties would be associated with more substantial price externalities, and our results support this hypothesis. However, the mechanism(s) that drove this result is less clear. We hypothesized that if the longer foreclosure process for UW2 foreclosures were causing blight, then the gap in estimated price externalities associated with RW2 and UW2 foreclosures would widen in later periods after the REO auction. We do not observe this effect. The gap in estimated price externalities between RW2 and UW2 foreclosures widened prior to the foreclosure auction, then remained relatively constant during the first 6 months after auction, then finally decreased. This trend suggests that UW2 foreclosures may suffer more serious blight than RW2 foreclosures before becoming REO stock. Heterogeneity in foreclosure impacts is likely rooted in blight suffered by properties before the REO auction. Finally, our last hypothesis was that both price externalities associated with RW2 and UW2 foreclosures would have similar distance decay patterns. We found this largely to be true.

Looking next to the different channels through which foreclosures are expected to generate neighborhood price externalities, our results suggest that most of the estimated externalities are associated with the blight channel. However, for RW2 foreclosures which sell within 3-6 months of the beginning of the foreclosure process, the timing of the negative price impact is suggestive of a mechanism which works through the supply or valuation channels. In our data, $66 \%$ of the RW2 foreclosures re-sold within o-6 months of the foreclosure auction. The only statistically significant estimated price externality associated with RW2 foreclosures in Model 3 occurred 3-6 months after the foreclosure auction. The magnitude of this price externality was small, and it decayed quickly.

Our results measuring heterogeneity in price externalities associated with different durations of the foreclosures process add additional context to other results in the literature. Daneshvary et al. (2011) found no negative neighborhood price impacts associated with short-sales. Our results suggest that the largest foreclosure externalities 
are a result of blight that occurs while the homeowner still occupies the house. The possibility of a short sale provides incentives for homeowners to maintain their property in order to increase the likelihood of a short sale that allows them to avoid foreclosure. Therefore, our results further support the notion that short-sales may be a preferred alternative because they help to provide incentives for homeowners to avoid blight. However, not all defaulted properties are good candidates for short sales. In these cases, quick action by banks to convert the property to REO stock are recommended for properties which are not likely to benefit from foreclosure "workout" efforts. Our results suggest a benefit for efforts that focus on identifying situations in which foreclosure workout programs are unlikely to be effective in order to minimize the neighborhood impact of an inevitable foreclosure. Alternatively, banks could also offer financial incentives to homeowners for maintaining their property throughout the foreclosure process. Such incentives could ameliorate neighborhood effects and help maintain the bank's asset value. However, the efficacy of incentives for inducing upkeep among homeowners in default and estimates of the market benefit of those upkeep behaviors will be necessary to understand the feasibility of this approach. In summary, foreclosure externalities were concentrated prior to the REO auction, and we did not observe further increases in neighborhood price externalities once the property had entered REO stock.

\section{Policy implications}

Price externalities associated with UW2 foreclosures imply some potential new considerations for policy regarding mortgage workout plans. Cutts (2008) note that foreclosure workout plans are more successful if implemented early in the foreclosure process because costs associated with the mortgage contract become too great as foreclosure process becomes lengthy. Our results suggest that costs associated with a failed workout plan might extend to the neighborhood as well, especially to the extent 
that failed workout plans extend the period from default to auction-the time in which UW2 properties are likely to suffer significant blight. These additional costs should be taken into consideration when assessing the cost/benefits of workout plans. Because the bank holding the defaulted mortgage is unlikely to be invested in other neighborhood properties, it is communities that largely bear the full cost of the externalities associated with long foreclosure processes. Communities can support programs to aide property upkeep; the additional tax receipts from avoided neighborhood price externalities might be used to justify such programs. Further work examining the cost and benefits of such programs and the parties to which these benefits accrue should be further evaluated (Wassmer (2011) and Ambrose and Capone (1996)). Future work should specifically examine the impact of foreclosures that occur after a failed workout plan.

\section{References}

Ambrose, B. W., and C. Capone. (1996). Cost-benefit analysis of single-family foreclosure alternatives. Journal of Real Estate Finance and Economics 13: 105-120.

Anselin, L. (1988). Spatial econometrics: methods and models. Dordrecht: Kluwer.

Cutts, A. C. (2008). Interventions in mortgage default: Policies and practices to prevent home loss and lower costs. Freddie Mac Working Paper \#08-o1.

Daneshvary, N. and T. M. Clauretie (2012). Toxic neighbors: Foreclosures and short-sales spillover effects from the current housing-market crash. Economic Inquiry 50 (1), $217-231$.

Daneshvary, N., T. M. Clauretie, and A. Kader (2011). Short-term own-price and spillover effects of distressed residential properties: The case of a housing crash. Journal of 
Real Estate Research 33 (2), 179 - 207.

ESRI (2014). ArcGIS Resources hot spot analysis (getis-ord gi*) (spatial statistics).

Goodman, J. L. J. (1993). A housing market matching model of the seasonality in geographic mobility. Journal of Real Estate Research 8 (1), 117.

Harding, J. P., E. Rosenblatt, and V. W. Yao (2009). The contagion effect of foreclosed properties. Journal of Urban Economics 66 (3), 164-178.

Immergluck, D. and G. Smith (2006). The impact of single-family mortgage foreclosures on neighborhood crime. Housing Studies 21 (6), 851-866.

Kan, J.. Sources of foreclosure data. MBA Research DataNotes (2008).

Kim, C. W., T. T. Phipps, and L. Anselin (2003). Measuring the benefits of air quality improvement: A spatial hedonic approach. Journal of Environmental Economics and Management 45, 24-39.

Kobie, T. F. and S. Lee (2011). The spatial-temporal impact of residential foreclosures on single-family residential property values. Urban Affairs Review 47 (1), 3-30. 10.1177/1078087410376614.

Lee, K.-y. (2008). Foreclosures price-depressing spillover effects on local properties: A literature review. Federal Reserve Bank of Boston, Community Affairs Discussion Paper (2008- 01).

Lee, L.-F. (2004). Asymptotic distributions of quasi-maximum likelihood estimators for spatial autoregressive models. Econometrica 72 (6), 1899-1925.

Leonard, T. and J. Murdoch (2009). The neighborhood effects of foreclosure. Journal of Geographical Systems 11 (4), 317-332-332.

Lin, Z., E. Rosenblatt, and V. Yao (2009). Spillover effects of foreclosures on 
neighborhood property values. The Journal of Real Estate Finance and Economics 38 (4), 387-407-407.

Mortgage Bankers Association (2014). Judicial vs nonjudicial foreclosure. Technical report.

Rogers, W. H. and W. Winter (2009). The impact of foreclosures on neighboring housing sales. Journal of Real Estate Research 31 (4), 455 - 479.

Rosen, S. (1974). Hedonic prices and implicit markets: product differentiation in perfect competition. Journal of Political Economy 72, 34-55.

Schuetz, J., V. Been, and I. G. Ellen (2008). Neighborhood effects of concentrated mortgage foreclosures. Journal of Housing Economics 17 (4), 306 - 319.

Stewart, L. (2010). 2009 state residential mortgage foreclosure laws. Technical report.

TDHCA (2006). A study of residential foreclosures in Texas. Technical report, Texas Department of Housing and Community Affairs.

Wassmer, R. W. (2011). The recent pervasive external effects of residential home foreclosure. Housing Policy Debate 21:2, 247-265

Zhang, L and T. Leonard (2014). Neighborhood impact of foreclosure: A quantile regression approach. Regional Science and Urban Economics 48 (2014), 133-143 


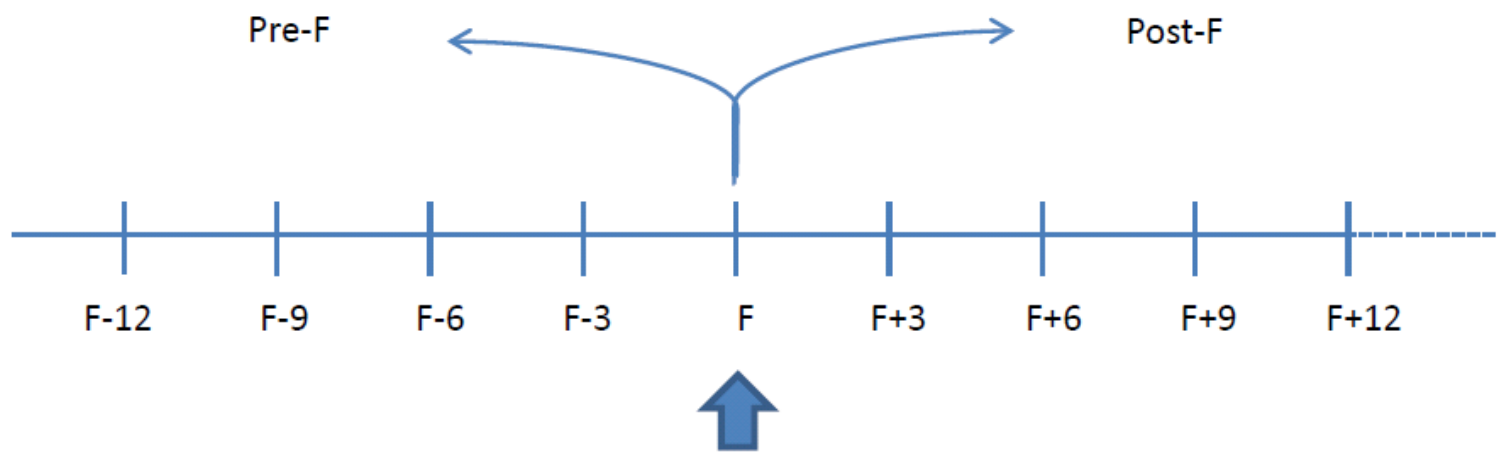

Foreclosure Auction (F)

Figure 1: Foreclosure process. This figure shows different time periods for RW2 and UW2 foreclosure processes used in this paper. 


\section{Ring 1 and Ring 2}

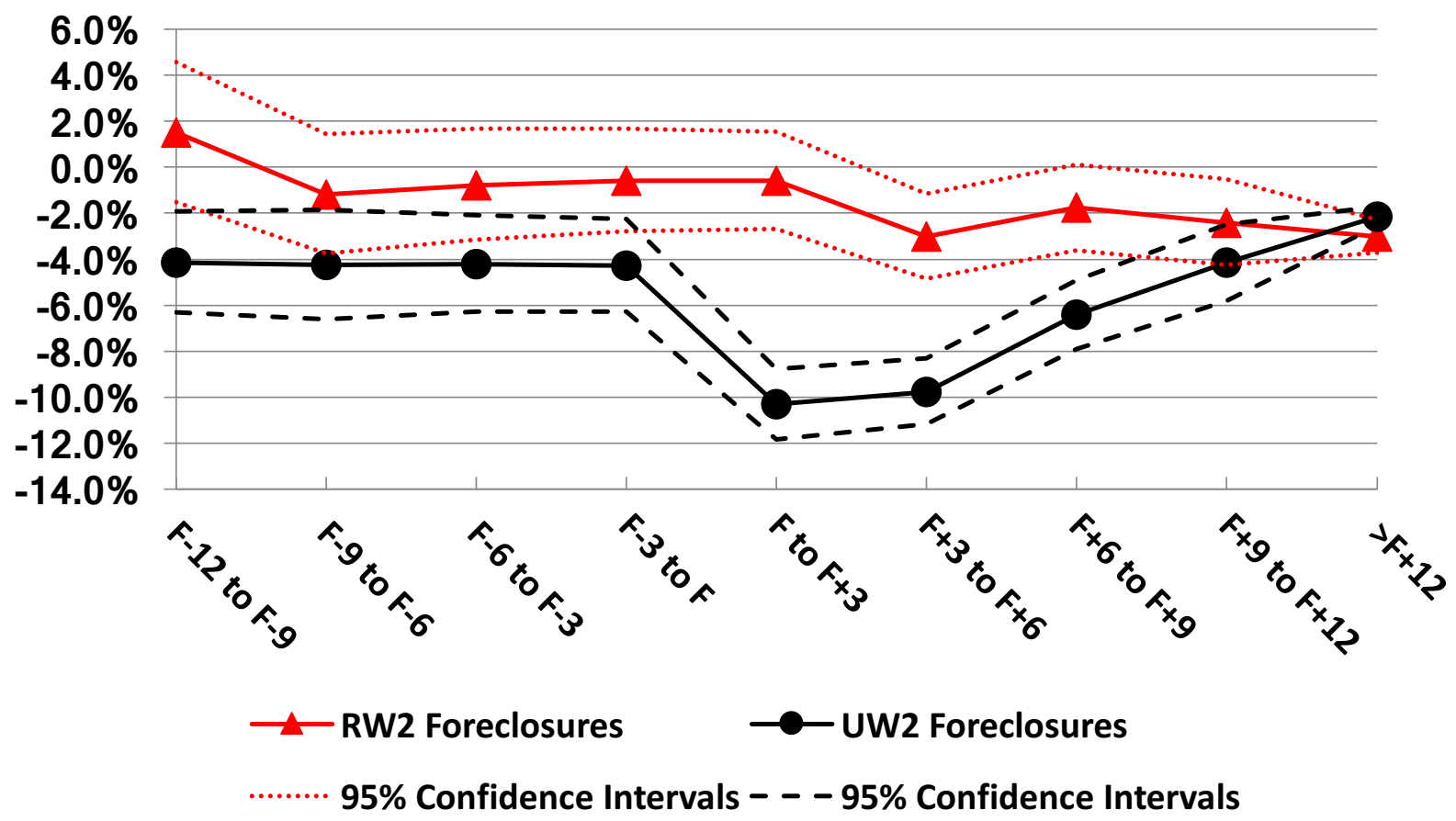

Ring 1

Ring 2

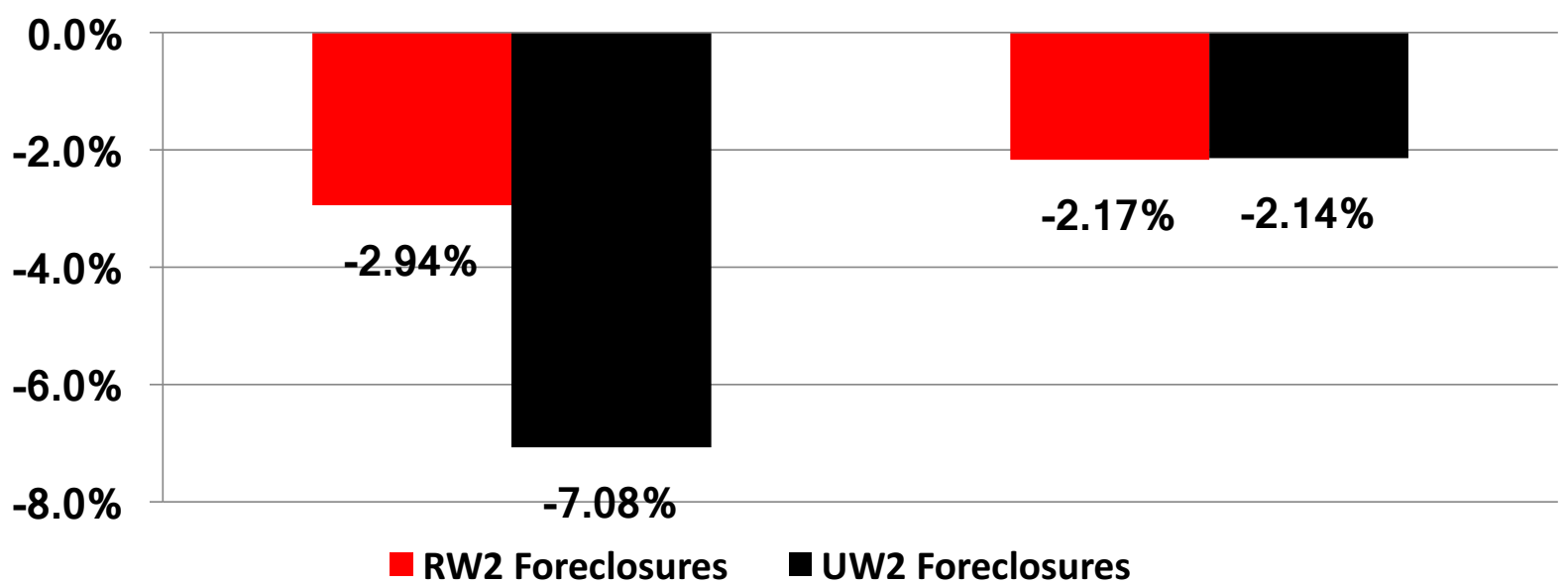

Figure 2: Aggregate Effects. The upper/lower panel displays the estimated foreclosure effects aggregated across both two rings/all time periods. 


\section{Ring 1}

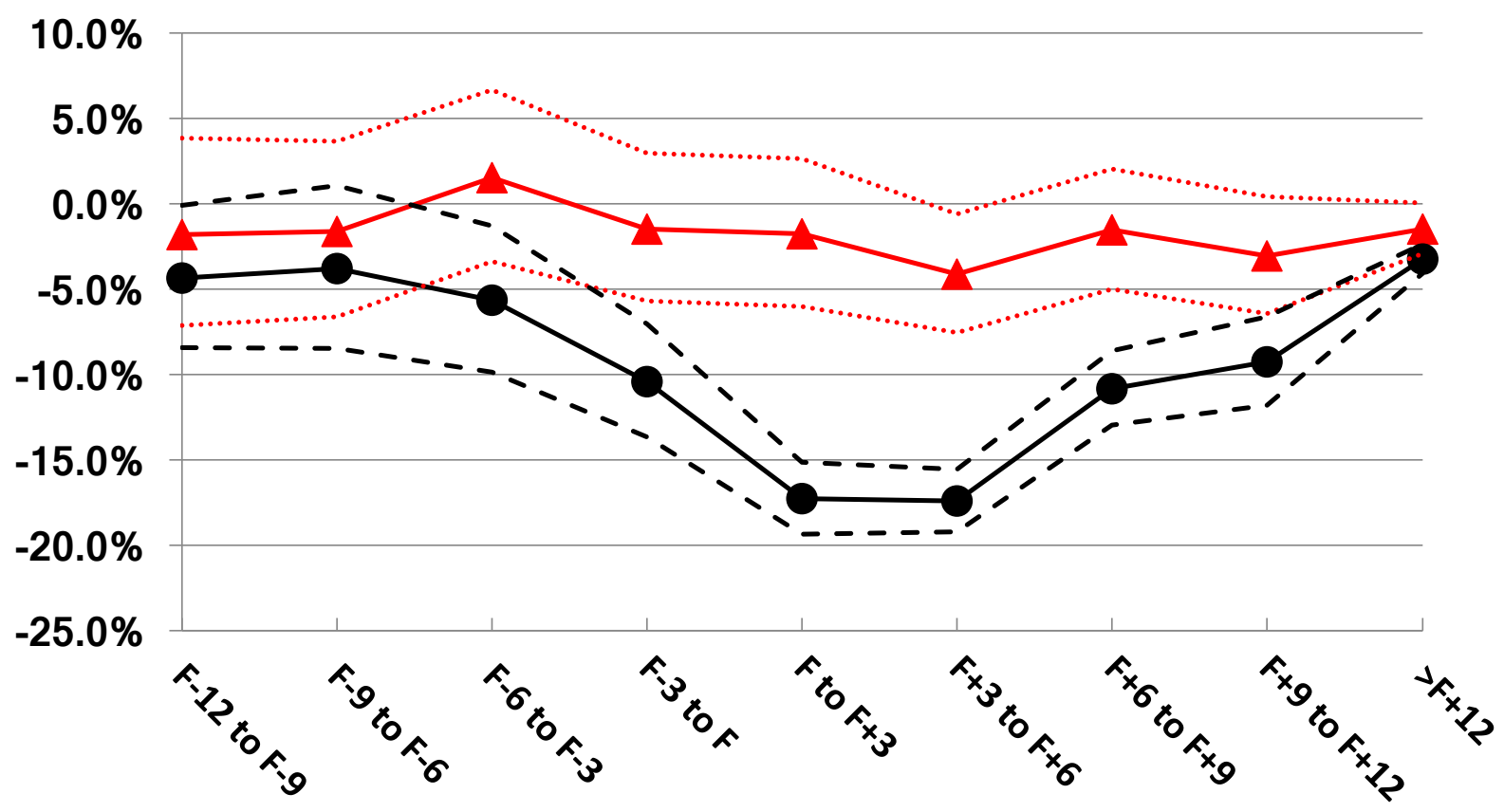

Ring 2

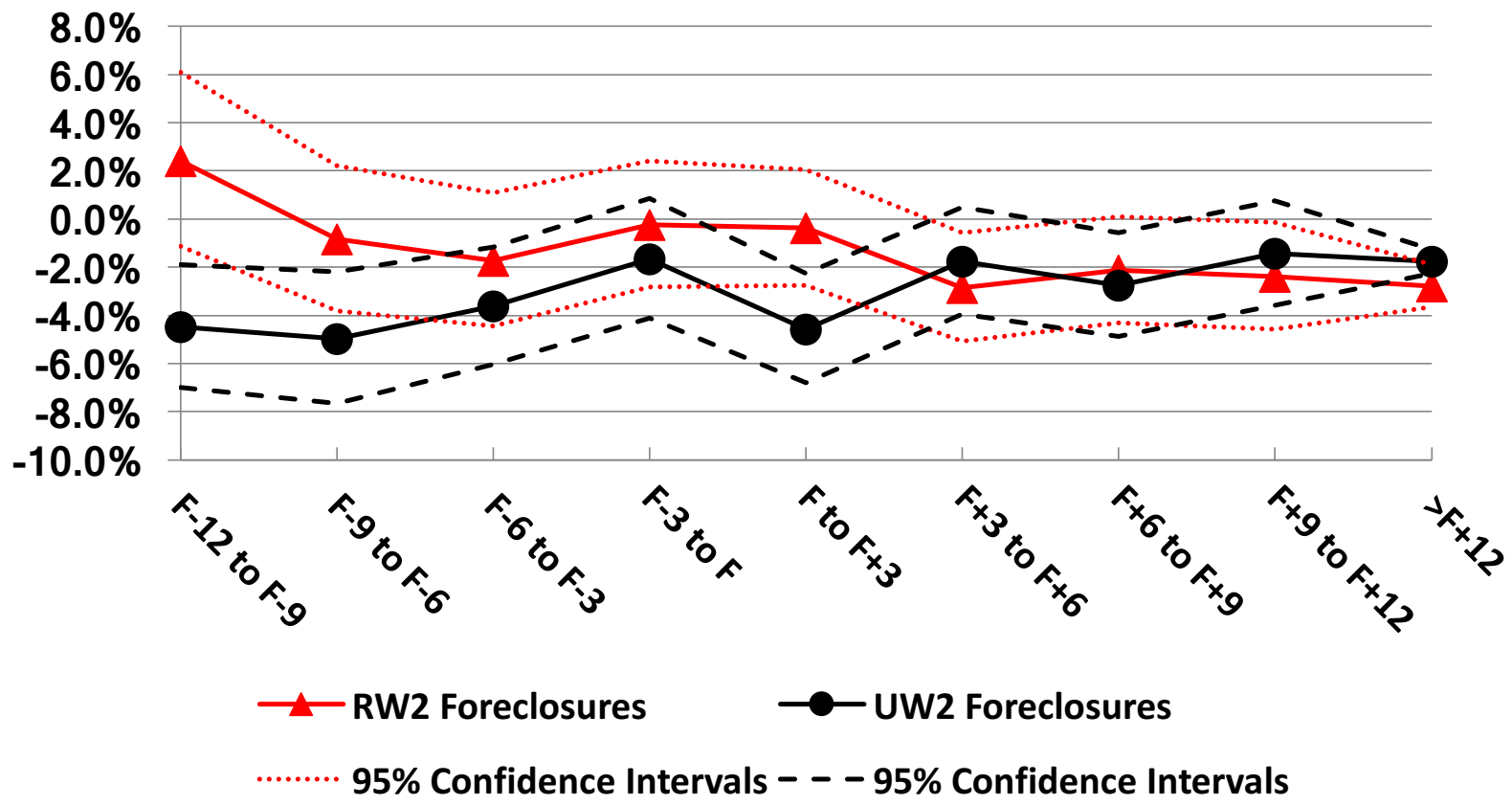

Figure 3: Time effect for Model 3. The upper/lower panel displays the estimated foreclosure effects resulting from foreclosures with 250 feet (Ring 1)/between 250 and 500 feet (Ring 2) of a non-distressed sale. 
Table 1: Variables, brief descriptions, and basic statistics

\begin{tabular}{|c|c|c|c|c|}
\hline Variable(s) & Description & Type & Mean & Std. Dev. \\
\hline sale price & Sales price & Continuous & $250,887.7$ & $372,602.3$ \\
\hline living area & Living area in 1000 sqft & Continuous & 2.147 & 1.088 \\
\hline lot area & Lot area in $1000 \mathrm{sqft}$ & Continuous & 10.108 & 10.177 \\
\hline baths & Number of bathrooms & Continuous & 2.296 & 0.878 \\
\hline age & Age of the house in yrs & Continuous & 36.666 & 21.892 \\
\hline pool & House with pool & Dummy & 0.140 & 0.347 \\
\hline 1 story & House with 1 story & Dummy & 0.711 & 0.453 \\
\hline 1.5 stories & House with 1.5 stories & Dummy & 0.116 & 0.320 \\
\hline slab & House with slab foundation & Dummy & 0.697 & 0.460 \\
\hline central heat & House with central heat & Dummy & 0.953 & 0.213 \\
\hline one fire & House with one fireplace & Dummy & 0.698 & 0.459 \\
\hline two fire & House with two fireplaces & Dummy & 0.073 & 0.260 \\
\hline attached garage & House with attached garage & Dummy & 0.789 & 0.408 \\
\hline attached carport & House with attached carport & Dummy & 0.020 & 0.139 \\
\hline detached carport & House with detached carport & Dummy & 0.008 & 0.089 \\
\hline condition 1 - 7 & Condition from low(1) to high(7) & Dummies & - & - \\
\hline $\mathrm{m} 1-\mathrm{m} 11$ & Month of sale & Dummies & - & - \\
\hline sd1 - sd13 & School district & Dummies & - & - \\
\hline
\end{tabular}

Note: detached garage, condition 8(best condition), m12(December), sd14(Sunnyvale school district), and 3 and more stories dummies are omitted. 
Table 2: Regression results

\begin{tabular}{|c|c|c|c|c|c|c|}
\hline & \multicolumn{2}{|c|}{$\begin{array}{l}\text { Model } 1 \\
\text { Time Effect }\end{array}$} & \multicolumn{2}{|c|}{$\begin{array}{l}\text { Model } 2 \\
\text { Distance Effect }\end{array}$} & \multicolumn{2}{|c|}{$\begin{array}{l}\text { Model } 3 \\
\text { Time and Distance Effect }\end{array}$} \\
\hline & Coeff. & Std. Error & Coeff. & Std. Error & Coeff. & Std. Error \\
\hline living area & 0.1688 & $0.0054^{* * *}$ & 0.1670 & $0.0054 * * *$ & 0.1690 & $0.0053^{* * *}$ \\
\hline lot area & 0.0058 & $0.0003^{* * *}$ & 0.0057 & $0.0003 * * *$ & 0.0058 & $0.0003^{* * *}$ \\
\hline baths & 0.1423 & $0.0067 * * *$ & 0.1439 & $0.0067^{* * *}$ & 0.1420 & $0.0066^{* * *}$ \\
\hline age & -0.0005 & $0.0003^{*}$ & -0.0003 & 0.0003 & -0.0005 & $0.0003^{* *}$ \\
\hline pool & 0.0724 & $0.0096 * * *$ & 0.0713 & $0.0096 * * *$ & 0.0725 & $0.0095^{* * *}$ \\
\hline condition1 & -0.7350 & $0.0777 * * *$ & -0.7434 & $0.0779 * * *$ & -0.7317 & $0.0771 * * *$ \\
\hline condition2 & -0.3780 & $0.0445 * * *$ & -0.3894 & $0.0446 * * *$ & -0.3675 & $0.0443 * * *$ \\
\hline condition3 & -0.1828 & $0.0346 * * *$ & -0.1938 & $0.0346 * * *$ & -0.1789 & $0.0345 * * *$ \\
\hline condition4 & -0.1452 & $0.0328 * * *$ & -0.1547 & $0.0328^{* * *}$ & -0.1447 & $0.0327^{* * *}$ \\
\hline condition5 & -0.0446 & 0.0324 & -0.0519 & 0.0325 & -0.0478 & 0.0323 \\
\hline condition 6 & 0.0210 & 0.0323 & 0.0143 & 0.0324 & 0.0159 & 0.0322 \\
\hline condition7 & 0.0852 & $0.0324 * * *$ & 0.0788 & $0.0324^{* *}$ & 0.0789 & $0.0323^{* *}$ \\
\hline M1 & 0.0919 & $0.0179 * * *$ & 0.0899 & $0.0179 * * *$ & 0.0909 & $0.0178 * * *$ \\
\hline M2 & 0.0927 & $0.0171 * * *$ & 0.0869 & $0.0170^{* * *}$ & 0.0880 & $0.0169 * * *$ \\
\hline M3 & 0.0955 & $0.0162 * * *$ & 0.0902 & $0.0162 * * *$ & 0.0916 & $0.0161^{* * *}$ \\
\hline M4 & 0.0865 & $0.0155^{* * *}$ & 0.0786 & $0.0155^{* * *}$ & 0.0875 & $0.0154 * * *$ \\
\hline M5 & 0.0770 & $0.0155^{* * *}$ & 0.0661 & $0.0154 * * *$ & 0.0748 & $0.0153 * * *$ \\
\hline M6 & 0.0756 & $0.0161 * * *$ & 0.0687 & $0.0161 * * *$ & 0.0739 & $0.0160 * * *$ \\
\hline M7 & 0.0750 & $0.0156 * * *$ & 0.0682 & $0.0156^{* * *}$ & 0.0736 & $0.0155^{* * *}$ \\
\hline M8 & 0.0538 & $0.0158 * * *$ & 0.0492 & $0.0158^{* * *}$ & 0.0552 & $0.0157^{* * *}$ \\
\hline M9 & 0.0370 & $0.0161^{* *}$ & 0.0332 & $0.0161^{* *}$ & 0.0333 & $0.0160 * *$ \\
\hline M10 & 0.0485 & $0.0166 * * *$ & 0.0439 & $0.0166^{* * *}$ & 0.0474 & $0.0165^{* * *}$ \\
\hline M11 & 0.0333 & $0.0179 *$ & 0.0307 & $0.0179 *$ & 0.0330 & $0.0178 *$ \\
\hline SD1 & -0.5829 & $0.0542 * * *$ & -0.5837 & $0.0543 * * *$ & -0.5794 & $0.0541 * * *$ \\
\hline SD2 & -0.5084 & $0.0532 * * *$ & -0.5125 & $0.0533 * * *$ & -0.5037 & $0.0531 * * *$ \\
\hline SD3 & -0.6993 & $0.0555^{* * *}$ & -0.6829 & $0.0555^{* * *}$ & -0.6959 & $0.0553^{* * *}$ \\
\hline SD4 & -0.7126 & $0.0530^{* * *}$ & -0.7106 & $0.0531^{* * *}$ & -0.7093 & $0.0530 * * *$ \\
\hline SD5 & -0.0922 & 0.0580 & -0.0997 & $0.0581 *$ & -0.0899 & 0.0578 \\
\hline SD6 & -0.6678 & $0.0544 * * *$ & -0.6712 & $0.0544 * * *$ & -0.6659 & $0.0543 * * *$ \\
\hline SD7 & -0.7641 & $0.0583^{* * *}$ & -0.7486 & $0.0583 * * *$ & -0.7639 & $0.0582^{* * *}$ \\
\hline SD8 & -0.7260 & $0.0537 * * *$ & -0.7321 & $0.0538 * * *$ & -0.7174 & $0.0537 * * *$ \\
\hline SD9 & -0.5370 & $0.0545^{* * *}$ & -0.5387 & $0.0546 * * *$ & -0.5359 & $0.0544 * * *$ \\
\hline SD10 & -0.7377 & $0.0544 * * *$ & -0.7425 & $0.0545^{* * *}$ & -0.7321 & $0.0543^{* * *}$ \\
\hline SD11 & -0.5783 & $0.0532 * * *$ & -0.5834 & $0.0532 * * *$ & -0.5765 & $0.0531 * * *$ \\
\hline SD12 & -0.8253 & $0.0552 * * *$ & -0.8291 & $0.0552 * * *$ & -0.8178 & $0.0550 * * *$ \\
\hline SD13 & -0.7684 & $0.0551^{* * *}$ & -0.7651 & $0.0552^{* * *}$ & -0.7674 & $0.0550 * * *$ \\
\hline 1 story & -0.0591 & $0.0104^{* * *}$ & -0.0613 & $0.0104 * * *$ & -0.0630 & $0.0103^{* * *}$ \\
\hline 1.5 story & -0.0348 & $0.0119 * * *$ & -0.0362 & $0.0120 * * *$ & -0.0357 & $0.0118^{* * *}$ \\
\hline slab & -0.1504 & $0.0103 * * *$ & -0.1467 & $0.0103 * * *$ & -0.1490 & $0.0102 * * *$ \\
\hline central heat & 0.3633 & $0.0160 * * *$ & 0.3740 & $0.0160 * * *$ & 0.3646 & $0.0159 * * *$ \\
\hline
\end{tabular}




\begin{tabular}{lllllll} 
one fire & 0.2206 & $0.0085^{* * *}$ & 0.2236 & $0.0086^{* * *}$ & 0.2177 & $0.0085^{* * *}$ \\
two fire & 0.3424 & $0.0169^{* * *}$ & 0.3473 & $0.0169 * * *$ & 0.3378 & $0.0167^{* * *}$ \\
Attached garage & -0.0353 & $0.0098^{* * *}$ & -0.0343 & $0.0099^{* * *}$ & -0.0382 & $0.0098^{* * *}$ \\
attached carport & -0.0779 & $0.0227^{* * *}$ & -0.0767 & $0.0227^{* * *}$ & -0.0780 & $0.0225^{* * *}$ \\
detached carport & -0.0737 & $0.0343^{* *}$ & -0.0750 & $0.0344^{* *}$ & -0.0727 & $0.0340^{* *}$ \\
$\rho_{07}$ & 0.0882 & $0.0038^{* * *}$ & 0.0875 & $0.0038^{* * *}$ & 0.0876 & $0.0038^{* * *}$ \\
$\rho_{06}$ & 0.0554 & $0.0038^{* * *}$ & 0.0564 & $0.0038^{* * *}$ & 0.0553 & $0.0038^{* * *}$ \\
$\rho_{05}$ & 0.0294 & $0.0027^{* * *}$ & 0.0294 & $0.0027^{* * *}$ & 0.0295 & $0.0027^{* * *}$ \\
Constant & 8.3283 & $0.0952^{* * *}$ & 8.3230 & $0.0949 * * *$ & 8.3605 & $0.0962 * * *$ \\
$\rho_{08}$ & 0.1020 & $0.0005^{* * *}$ & 0.1020 & $0.0005^{* * *}$ & 0.1010 & $0.0005^{* * *}$ \\
$R^{2}$ & 0.8060 & & 0.8049 & & 0.8099 & \\
$\mathrm{~N}$ & 12465 & & 12465 & & 12465 & \\
\hline
\end{tabular}

* Significant at $10 \% ; * *$ Significant at $5 \% ;{ }^{* * *}$ Significant at $1 \%$

Table 3: Regression results for time/distance effects

RW2 Foreclosures UW2 Foreclosures

Coeff. Std. Err. Coeff. Std. Err.

\begin{tabular}{lllll}
\hline \multicolumn{5}{c}{ Time Effect (Model 1) } \\
F-12 to F-9 & 0.0148 & 0.0153 & -0.0422 & $0.0117^{* * *}$ \\
F-9 to F-6 & -0.0118 & 0.0134 & -0.0435 & $0.0127^{* * *}$ \\
F-6 to F-3 & -0.0078 & 0.0124 & -0.0429 & $0.0111^{* * *}$ \\
F-3 to F & -0.0059 & 0.0114 & -0.0439 & $0.0107^{* * *}$ \\
F to F+3 & -0.0060 & 0.0108 & -0.1088 & $0.0087^{* * *}$ \\
F+3 to F+6 & -0.0308 & $0.0097^{* * *}$ & -0.1027 & $0.0081^{* * *}$ \\
F+6 to F+9 & -0.0178 & $0.0097^{*}$ & -0.0664 & $0.0081^{* * *}$ \\
F+9 to F+12 & -0.0244 & $0.0098^{* *}$ & -0.0425 & $0.0088^{* * *}$ \\
$>$ F+12 & -0.0305 & $0.0037^{* * *}$ & -0.0216 & $0.0021^{* * *}$ \\
\hline \multicolumn{5}{c}{ Distance Effect (Model 2$)$} \\
Ring 1 & -0.0299 & $0.0051^{* * *}$ & -0.0734 & $0.0034^{* * *}$ \\
Ring 2 & -0.0220 & $0.0029 * * *$ & -0.0216 & $0.0021^{* * *}$ \\
\hline
\end{tabular}

* Significant at $10 \%$; ** Significant at $5 \%$; *** Significant at $1 \%$ 
Table 4: Regression results for time and distance effects (Model 3)

\begin{tabular}{|c|c|c|c|c|}
\hline & \multicolumn{2}{|c|}{0 to 250} & \multicolumn{2}{|r|}{250 to 500} \\
\hline & Coeff. & Std. Err. & Coeff. & Std. Err. \\
\hline \multicolumn{5}{|c|}{ RW2 Foreclosures } \\
\hline $\mathrm{F}-12$ to $\mathrm{F}-9$ & -0.0184 & 0.0285 & 0.0239 & 0.0180 \\
\hline F-9 to F-6 & -0.0163 & 0.0266 & -0.0084 & 0.0155 \\
\hline $\mathrm{F}-6$ to $\mathrm{F}-3$ & 0.0149 & 0.0253 & -0.0173 & 0.0144 \\
\hline $\mathrm{F}-3$ to $\mathrm{F}$ & -0.0148 & 0.0224 & -0.0024 & 0.0134 \\
\hline $\mathrm{F}$ to $\mathrm{F}+3$ & -0.0180 & 0.0225 & -0.0038 & 0.0123 \\
\hline $\mathrm{F}+3$ to $\mathrm{F}+6$ & -0.0422 & $0.0185^{* *}$ & -0.0290 & $0.0118 * *$ \\
\hline $\mathrm{F}+6$ to $\mathrm{F}+9$ & -0.0155 & 0.0182 & -0.0215 & $0.0115^{*}$ \\
\hline $\mathrm{F}+9$ to $\mathrm{F}+12$ & -0.0313 & $0.0180 *$ & -0.0241 & $0.0116 * *$ \\
\hline$>\mathrm{F}+12$ & -0.0148 & $0.0077 * * *$ & -0.0282 & $0.0046 * * *$ \\
\hline \multicolumn{5}{|c|}{ UW2 Foreclosures } \\
\hline $\mathrm{F}-12$ to $\mathrm{F}-9$ & -0.0445 & $0.0222 * *$ & -0.0459 & $0.0136 * * *$ \\
\hline F-9 to F-6 & -0.0390 & 0.0253 & -0.0510 & $0.0147 * * *$ \\
\hline F-6 to F-3 & -0.0584 & $0.0231 * *$ & -0.0369 & $0.0129 * * *$ \\
\hline $\mathrm{F}-3$ to $\mathrm{F}$ & -0.1100 & $0.0189 * * *$ & -0.0169 & 0.0129 \\
\hline $\mathrm{F}$ to $\mathrm{F}+3$ & -0.1895 & $0.0130 * * *$ & -0.0467 & $0.0121 * * *$ \\
\hline $\mathrm{F}+3$ to $\mathrm{F}+6$ & -0.1912 & $0.0113 * * *$ & -0.0177 & 0.0116 \\
\hline $\mathrm{F}+6$ to $\mathrm{F}+9$ & -0.1146 & $0.0124 * * *$ & -0.0280 & $0.0113^{* *}$ \\
\hline $\mathrm{F}+9$ to $\mathrm{F}+12$ & -0.0970 & $0.0146 * * *$ & -0.0144 & 0.0112 \\
\hline$>\mathrm{F}+12$ & -0.0330 & $0.0045 * * *$ & -0.0179 & $0.0026 * * *$ \\
\hline
\end{tabular}

* Significant at $10 \%$; ** Significant at $5 \% ; * * *$ Significant at $1 \%$ 